Journal of Current and Advance Medical Research

July 2021, Vol. 8, No. 2, pp. 125-129

http://www.banglajol.info/index.php/JCAMR ISSN

(Print) 2313-447X

ISSN (Online) 2413-323X

NLM Catalog ID 101673828

DOI: https://doi.org/ 10.3329/jcamr.v8i2.57438

ORIGINAL ARTICLE OPEN $\bigcirc$ ACCESS

\title{
Role of Serum B-type Natriuretic Peptide before and after 2 hours of Spontaneous Breathing Trial among Patients under Mechanical Ventilation
}

\author{
AKM Faizul Hoque ${ }^{1}$, Manas Kanti Mazumder ${ }^{2}$, Omma Hafsa Any ${ }^{3}$, Sharna Moin ${ }^{4}$, Rocky Das \\ Gupta $^{5}$, Shahadat Hossain Polash ${ }^{6}$, Rajan Mondol ${ }^{7}$, Sheikh Ul Alam ${ }^{8}$
}

\begin{abstract}
${ }^{1}$ Associate Professor, Department of Anaesthesia, Analgesia and Intensive Care Medicine, Bangabandhu Sheikh Mujib Medical University Hospital, Dhaka, Bangladesh; ${ }^{2}$ Medical Officer, Department of Anaesthesia, Analgesia And Intensive Care Medicine, Bangabandhu Sheikh Mujib Medical University Hospital, Dhaka, Bangladesh; ${ }^{3}$ Associate Professor, Department of Pharmacology \& Therapeutics, Army Medical College, Jashore, Bangladesh; ${ }^{4}$ Assistant Professor, Department of Anatomy, Army Medical College, Jashore, Bangladesh; ${ }^{5}$ Medical Officer, 250 bedded General Hospital, Chittagong, Bangladesh; ${ }^{6}$ Resident (CCM), Department of Anaesthesia Analgesia \& Intensive Care Medicine, Bangabandhu Sheikh Mujib Medical University Hospital, Dhaka, Bangladesh; ${ }^{7}$ Resident (CCM), Department of Critical Care Medicine, Bangladesh Institute of Research and Rehabilitation in Diabetes, Endocrine and Metabolic Disorders, Dhaka, Bangladesh; ${ }^{8}$ Resident (CCM), Department of Critical Care Medicine, Bangladesh Institute of Research and Rehabilitation in Diabetes, Endocrine and Metabolic Disorders, Dhaka, Bangladesh
\end{abstract}

\section{Abstract}

[Received on: 11 April 2021; Accepted on: 2 My 2021; Published on: 1 July 2021]

Background: Weaning of a patient from mechanical ventilation is very important for the outcomes of the patients. Objective: The purpose of the study was to evaluate the serum level of BNP before and after 2hours of spontaneous breathing trial (SBT) among patients under mechanical ventilation. Methodology: This prospective cohort study was conducted in the Department of Anesthesia, Analgesia and Intensive Care Medicine at Bangabandhu Sheikh Mujib Medical University, Dhaka, Bangladesh over a period of 2 years. Study population was selected for weaning from mechanical ventilation support for the first time in the age group of more than 18 years with both sexes. Plasma BNP level of all patients was measured before and after 2 hours of spontaneous breathing trial. Results: A total number of 30 patients were recruited for this study. One-third (33.3\%) of the patients failed on SBT. The mean percent changes of BNP $(\mathrm{pg} / \mathrm{ml})$ during 2-h of SBT in weaning success and failure groups were $38.41 \pm 9.379$ and $59.51 \pm 2.940$ respectively $(\mathrm{p}=0.01)$. The receiver-operating characteristic curve analysis for BNP as a predictor of weaning outcome, showed that the area under the curve (AUC) was 0.89. Conclusion: In conclusion BNP is currently a good predictor of different cardiac diseases. [Journal of Current and Advance Medical Research, July 2021;8(2):125-129]

Keyword: Plasma BNP; anesthesia; analgesia; intensive care

Correspondence: Dr. AKM Faizul Hoque, Associate Professor, Department of Anaesthesia, Analgesia and Intensive Care Medicine, Bangabandhu Sheikh Mujib Medical University Hospital, Shahbag, Dhaka, Bangladesh; Email: akmfaizul@ gmail.com; Cell no.: +880 ...

Cite this article as: Hoque AKMF, Mazumder MK, Any OH, Moin S, Gupta RD, Polash SH, Mondol R, Alam SU. Role of Serum B-type Natriuretic Peptide before and after 2 hours of Spontaneous Breathing Trial among Patients under Mechanical Ventilation. J Curr Adv Med Res 2021;8(2):125-129

Funding: This study has been performed without any funding from outside else.

Conflict of Interest: There was no conflict of interest to any of the authors.

Contributions to authors: Hoque AKMF, Mazumder MK, Any OH had involved in the protocol preparation, data collection, statistical analysis. Moin S, Gupta RD, Polash SH, Mondol R, Alam SU involved in the manuscript preparation.

Copyright: (O2021. Hoque et al. Published by Journal of Current and Advance Medical Research. This article is published under the Creative Commons CC BY-NC License (https://creativecommons.org/licenses/by-nc/4.0/). This license permits use, distribution and reproduction in any medium, provided the original work is properly cited, and is not used for commercial purposes. 


\section{Introduction}

BNP is secreted by ventricular cardiomyocytes in response to myocardial stretch by volume or pressure overload ${ }^{1-2}$. During two hours of SBT which is currently the most accurate index for predicting the weaning success, there is an increase of in cardiac preload and afterload of the both side of heart caused by intrathoracic pressure shift, increase catecholamine secretion and work of breathing ${ }^{3}$. This increased volume and pressure shifting precipitate weaning induced cardiac dysfunctions like weaning induced pulmonary oedema (WiPO) and weaning induced cardiac ischemia ${ }^{4}$. Though both of them contribute weaning failure, impact of WiPO is more significant. An increase of plasma BNP during SBT, can demonstrate these cardiac dysfunctions ${ }^{4-5}$.

BNP has diuretic, natriuretic and antihypertensive effect. It has also anti-proliferative effect on fibroblast in progressive heart failure. The recommended threshold of less than $100 \mathrm{pg} / \mathrm{ml}$ to rule out heart failure, more than $500 \mathrm{pg} / \mathrm{ml}$ to rule in heart failure and intermediate range of 100 to $500 \mathrm{pg} / \mathrm{ml}$ cannot be used alone to rule out or rule in heart failure ${ }^{6}$. BNP is a sensitive $(>98 \%)$ and specific $(>95.0 \%)$ serum marker for cardiovascular dysfunction ${ }^{7}$. Falsely high level of BNP may be seen in females with advancing age and in the presence of renal failure ${ }^{8-13}$.

BNP is the most reliable hormonal marker for left ventricular dysfunction and its plasma levels correlate closely with indices of systolic function in patients with stable and decompensated heart failure $^{8}$. BNP has been proposed as a novel biomarker to help guide decision making in the readiness for the liberation of mechanical ventilation following a spontaneous breathing trial $^{14}$. Current evidence on the predictive ability of $\mathrm{BNP}$ on weaning failure has been uncertain, and has not been integrated into clinical practice guideline. This present study was undertaken to evaluate the plasma level of B-type natriuretic peptide (BNP) as a predictor of weaning outcome among the patients under mechanical ventilation.

\section{Methodology}

This study was a prospective cohort study. This study was carried out from July 2018 to June 2020 for a period of two (02) years. This study was conducted in the Department of Anaesthesia, Analgesia and Intensive Care Medicine at Bangabandhu Sheikh Mujib Medical University,
Dhaka, Bangladesh. Data were taken after the approval of Institutional Review Board (IRB). Patients who were considered for liberation from mechanical ventilation support for the first time in the age group of more than 18 years with both sexes were selected as the study population. Patients with pre-existing diseases that elevate the plasma BNP level were excluded from the study. Weaning criteria was selected by ICU consultant following the standard ICU protocol for every patient enrolled in this study. Patients were subdivided into weaning success and weaning failure groups according to the outcome of weaning process. This study population was selected by purposive sampling technique. All patients who were intubated and had shown improvement or resolution of the underlying cause of respiratory failure or sedation stopped during the previous 48 hours and analgesia might continue were included in this study. Patients with heart failure (right or left), pulmonary hypertension, valvular heart diseases and atrial fibrillation or patients having Acute (creatinine $>350 \mathrm{mmol} / \mathrm{l}$ ) or Chronic renal diseases under Renal Replacement Therapy (RRT), cirrhosis of liver, patients with tracheostomy, patients with hyperthyroidism as this condition may be associated with increased BNP level or patients with prolonged cardiac arrest with poor neurological prognosis were excluded from this study. During follow-Up the variables like date of start of invasive Mechanical Ventilation in ICU, invasive mechanical ventilation outside before admission to the ICU, date and time of stopping sedation, date and time of stopping inotropes, date of Weaning were recorded. Patient details like age, sex, address was documented in the case record form (CRF) supplied. The informed written consent was taken from patient's relatives. Detailed history and clinical examination findings were documented in case record form (CRF). Initial mortality prediction was done by APACHE-2 (Acute physiology and Chronic Health Evaluation) and qSOFA (quick Sequential Organ Failure Assessment). All previous investigations done for these patients were recorded in the investigation record form in ICU. Relevant investigations for this study like BNP and ABG were recorded in the case record form (CFR). Statistical analysis was performed by Windows based software named as Statistical Package for Social Science (SPSS), versions 22.0 (IBM SPSS Statistics for Windows, Version 22.0. Armonk, NY: IBM Corp). Continuous data that were normally distributed were summarized in terms of the mean, standard deviation, median, minimum, maximum and number of observations. Categorical data were summarized in terms of frequency counts and percentages. For end points analysis, Chi-square 
test was used for categorical data and Student t Test for continuous data.

\section{Results}

A total number of 30 patients were recruited for this study. Of the 30 patients included in the study $20(67.7 \%)$ patients were in the weaning success group designated as Group $\mathrm{A}$ and the rest $10(33.3 \%)$ patients were in the weaning failure group designated as Group B. The plasma BNP level was measured in all patients before and after 2-h of SBT, which was significantly higher in weaning failure group than weaning success group $(p=0.01)$, the mean percentage change of BNP in during 2-h of SBT was evaluated by ROC curve. In weaning success group, the most common age group was 40 to 60 years which was $14(70.0 \%)$ cases followed by 60 to 72 years and 32 to 40 years age group which was $4(20.0 \%)$ cases and $2(10.0 \%)$ cases respectively. In weaning failure group, the most common age group was 40 to 60 years which was $5(50.0 \%)$ cases followed by 60 to 72 years and 32 to 40 years age group which was $4(40.0 \%)$ cases and $1(10.0 \%)$ case respectively. The mean age with $\mathrm{SD}$ of weaning success and failure group were $54.90 \pm 9.78$ years and $57.60 \pm 10.09$ years respectively. The age range of study population was 32 to 72 years. The difference of age group of weaning success and failure groups were not statistically significant $(\mathrm{p}$ value $=0.48)($ Table 1$)$.

Table 1: Age Distribution of Study Population. Group-A (Weaning success) and Group-B (Weaning failure) $(\mathrm{n}=\mathbf{3 0})$

\begin{tabular}{|l|c|c|c|}
\hline \multirow{2}{*}{ Age Group } & \multicolumn{2}{|c|}{ Weaning Group } & \multirow{2}{*}{ P value } \\
\cline { 2 - 3 } & Group-A & Group-B & \\
\hline 32 to 40 Years & $2(10.0 \%)$ & $1(10.0 \%)$ & \multirow{2}{*}{$0.49 *$} \\
\hline 40 to 60 Years & $14(70.0 \%)$ & $5(50.0 \%)$ & \\
\hline 60 to 72 Years & $4(20.0 \%)$ & $4(40.0 \%)$ & \\
\hline Mean \pm SD & $54.9 \pm 9.787$ & $57.6 \pm 10.091$ & $0.48 * *$ \\
\hline
\end{tabular}

Range: 32 to 72 years; *Chi-square test was performed to see the level of significance; $* * \mathrm{P}$ value was calculated by unpaired $t$ test to see the level of significance.

Before SBT, the mean with standard deviation of BNP in male and female was $44.97 \pm 20.402$ and $67.70 \pm 22.254$ respectively. The difference of BNP value of male and female before SBT was statistically significant $(p=0.001)$. After SBT, the mean with standard deviation of BNP in male and female was $146.51 \pm 130.28$ and $302.60 \pm 130.679$ respectively. The difference of BNP value of male and female after SBT was statistically significant $(\mathrm{p}=0.007)$ (Table 2).
Table 2: BNP level $(\mathrm{pg} / \mathrm{ml})$ in Gender among Study Population $(\mathrm{n}=\mathbf{3 0})$

\begin{tabular}{|l|c|c|c|}
\hline BNP Value & Gender & Mean \pm SD & P value \\
\hline Before SBT & Male & $44.97 \pm 20.40$ & \multirow{2}{*}{0.001} \\
\cline { 2 - 3 } & Female & $67.70 \pm 22.25$ & \\
\hline $\begin{array}{l}\text { After 2-h of } \\
\text { SBT }\end{array}$ & Male & $146.51 \pm 130.28$ & \multirow{2}{*}{0.007} \\
\cline { 2 - 3 } & Female & $302.60 \pm 130.67$ & \\
\hline
\end{tabular}

SBT- Spontaneous breathing trail. P value was calculated by unpaired t test to see the level of significance.

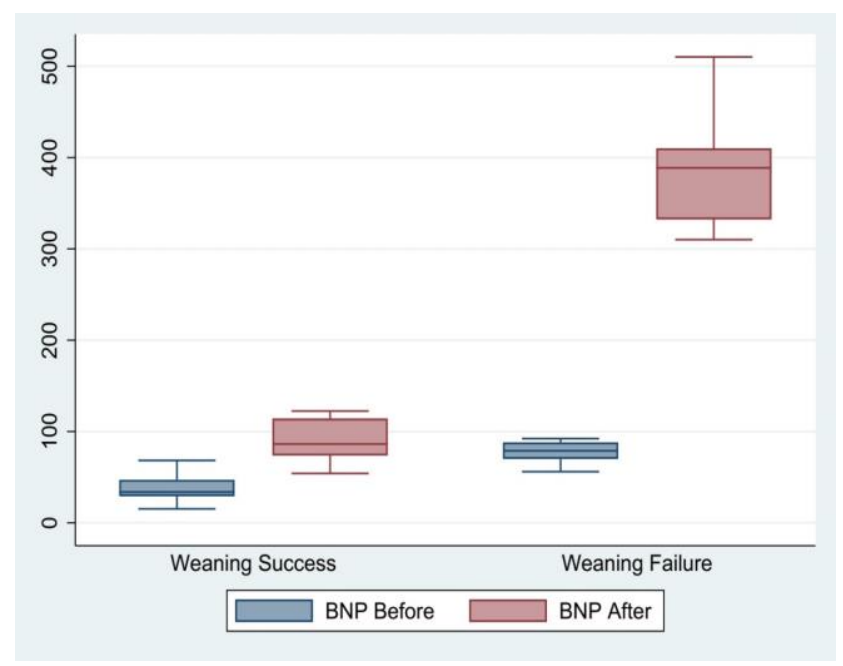

Figure I: Showing the BNP Level (pg/ml) before and After SBT between Weaning Success and Failure Groups

The boxplot shows the different values of BNP in weaning success and failure groups before and after SBT. There were no outliers in success group. However, in failure group after SBT there was no outlier. The median value of BNP was not equal in success and failure group which had reflected the disparity of values of BNP before and after SBT. In contrast the median BNP value of failure group before SBT was below the normal value of BNP and there was a very high median value of BNP after SBT.

Table 3: The Mean Percent Change in plasma BNP level (pg/ml) during 2-hours of SBT $(\mathrm{n}=30)$

\begin{tabular}{|l|c|c|}
\hline Weaning Group & Mean \pm SD & P value \\
\hline Success Group & $38.41 \pm 9.379$ & \multirow{2}{*}{0.01} \\
\hline Failure Group & $59.51 \pm 2.940$ & \\
\hline
\end{tabular}

$P$ value was calculated by unpaired $t$ test to see the level of significance.

Table 3 showed the mean percent change in plasma BNP level during 2-hours of SBT. The mean percent changes of BNP with standard deviation of weaning success and failure groups were $38.41 \pm 9.379$ and $59.51 \pm 2.940$ respectively. The 
difference of changes of BNP between these two groups were statistically significant $(\mathrm{p}=0.01)$ (Table $3)$.

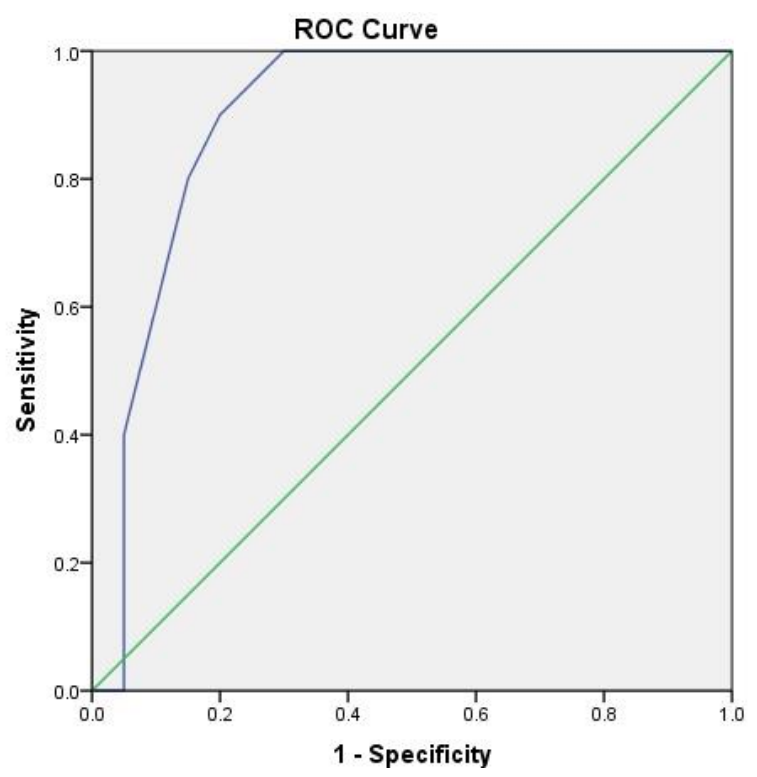

\section{Figure II: Predictive value of percent change of BNP in Weaning failure}

The area under the ROC curve for percent change of BNP in SBT failure was 0.89 (95\% CI 0.782$1.00)$. The best percentage change was 42.5 , with a sensitivity of $90 \%$, a specificity of $80 \%$ (Figure II).

\section{Discussion}

The successful weaning from mechanical ventilation depends not only on adequate respiratory strength and endurance but also an optimal performance of other organs including heart ${ }^{15}$. Patient's cardiovascular function may be compromised by alteration in lung volumes and intrathoracic pressure during withdrawal of mechanical ventilation and may be an important cause of weaning failure ${ }^{16}$.

Plasma B-type natriuretic peptide (BNP) is secreted by ventricular cardiomyocyte in response to myocardial stretch and it is correlated to left ventricular filling pressure ${ }^{17}$. Since cardiac dysfunction can cause weaning failure in mechanically ventilated patients, the aim of this study is to evaluate the role plasma B-type natriuretic peptide (BNP) as a predictor of weaning outcome.

A total number of 30 patients were recruited for this study after fulfilling the inclusion and exclusion criteria. According to the outcome of SBT they were subdivided into two groups, weaning success
( $\mathrm{n}=20)$ and weaning failure group $(\mathrm{n}=10)$. Regarding age distribution in weaning success group and weaning failure group the most common age group was 40 to 60 years. The difference of age group of weaning success and failure groups were not statistically significant $(\mathrm{p}=0.49)$. From this finding it is very clear that the mean age of the patients in weaning success and failure groups were more or less equivalent $(p=0.48)$. Therefore, the result is not bias based on the age of the patients. The similar age distribution is also reported by Mekontso-Dessap et $\mathrm{al}^{5}$ and have stated that the age group are 57 years which is consistent with the present study. Chien et al ${ }^{18}$ have performed a study and have found that most of the patients are in this age group under mechanical ventilation which is similar to this present study.

The mean BNP values among male and female were recorded in this study and found that the mean BNP values were higher in female than male both before and after SBT, which was statistically significant $(\mathrm{p}=0.001)$. Redfield et $\mathrm{al}^{13}$ mentioned that BNP level is higher in females compared to males in all age groups. The exact reason for this is still under investigation but may have to do with either the impact of estrogen, with the high estrogen levels causing higher BNP levels or the role of testosterone on lowering the level of $\mathrm{BNP}^{21}$. The study finding is similar to the study finding of Redfield et $\mathrm{al}^{13}$ in which BNP level is $32.0 \%$ higher in female than male $(\mathrm{CI}=15 \%$ to $51 \%, \mathrm{p}<0.001)$ by Shionogi assay and $80 \%$ higher by Bisite assay $(\mathrm{CI}=50 \%$ to $116 \%, \mathrm{p}<0.001)$.

The boxplot shows the change of BNP level (pg/ml) between weaning success and failure groups. Through this boxplot we can see the disparity of BNP level between the two weaning groups before and after 2-h of SBT. BNP is a known cardiobiomarker which is potentially elevated due to some cardiac diseases (Maise et al. 2002), it can also increase after unsuccessful weaning ${ }^{5,9}$. In this study there was an initial increase of BNP level before SBT which was due to intrathoracic pressure shifting and stress at the onset of $\mathrm{SBT}^{2}$. BNP elevation before SBT is an independent factor for weaning failure which is consistent with this study finding 5 .

The percent change in the BNP level has been evaluated by using ROC curve. The area under the curve was 0.89 . It was found that an increase of BNP level less than $42.5 \%$ from base line had the best combination of sensitivity (90\%) and specificity $(80.0 \%)$ in predicting extubation failure. Chien et $\mathrm{al}^{18}$ found an increase of BNP less than 
20.0\% during SBT had the best combination of sensitivity (91\%) and specificity (88\%). El Maraghi et $\mathrm{al}^{19}$ had similar finding. The disparity in predictive value between this study and other could be due to small sample size and large-scale change of BNP level during SBT. In this study 21 out of 30 patients had hypertension which was significantly higher than other studies, could be a cause of high BNP level among the study population. Similarly, significant changes were found in this study in $\mathrm{ABG}$ and clinical variables during breathing trail, regarding the study of Chien et $\mathrm{al}^{18}$ and EI Maraghi ${ }^{19}$. These changes had an impact on plasma BNP elevation. Acute hypoxia $\left(\mathrm{PAO}_{2}\right.$ less than $60 \mathrm{~mm}$ of $\mathrm{Hg}$ and Saturation percent less than 90) results rapid increase of cardiac BNP gene transcription which significantly rise plasma $\mathrm{BNP}^{20}$. Amdani et $\mathrm{al}^{21}$ states that there is significant positive correlation between natriuretic peptide and partial pressure of carbon dioxide $\left(\mathrm{Paco}_{2}\right)$, which is consistent with this study findings. After all the discussion it is found that BNP have some predictive role regarding weaning outcome.

\section{Conclusion}

Plasma BNP level was increased both in weaning success and weaning failure group during SBT. But it was significantly increased in weaning failure group which was evaluated by ROC curve. So, plasma BNP level can be used to predict the weaning outcome of mechanically ventilated patients. Plasma BNP measurement can be an effective parameter to predict weaning outcome in mechanically ventilated patients and should be measured regularly.

\section{Reference}

1. Ely EW, Baker AM, Dunagan DP, Burke HL, Smith AC, Kelly PT, et al. Effect on the duration of mechanical ventilation of identifying patients capable of breathing spontaneously. New England Journal of Medicine. 1996;335(25):1864-9

2. Boomsma F, van den Meiracker AH. Plasma A-and B-type natriuretic peptides: physiology, methodology and clinical use. Cardiovascular research. 2001;51(3):442-9

3. Lemaire F, Teboul JL, Cinotti L, Giotto G, Abrouk F, Steg $\mathrm{G}$, et al. Acute left ventricular dysfunction during unsuccessful weaning from mechanical ventilation. Anesthesiology. 1988;69(2):171-9

4. Bedet A, Tomberli F, Prat G, Bailly P, Kouatchet A, Mortaza $\mathrm{S}$, et al. Myocardial ischemia during ventilator weaning: a prospective multicenter cohort study. Critical Care. 2019;23(1):1-9

5. Dessap AM, Katsahian S, Roche-Campo F, Varet H, Kouatchet A, Tomicic V, et al. Ventilator-associated pneumonia during weaning from mechanical ventilation: role of fluid management. Chest. 2014;146(1):58-65

6. Maries L, Manitiu I. Diagnostic and prognostic values of Btype natriuretic peptides (BNP) and $\mathrm{N}$-terminal fragment brain natriuretic peptides (NT-pro-BNP). Cardiovascular journal of Africa. 2013;24(7):286-9

7. Dao Q, Krishnaswamy P, Kazanegra R, Harrison A, Amirnovin R, Lenert L, et al. Utility of B-type natriuretic peptide in the diagnosis of congestive heart failure in an urgentcare setting. Journal of the American College of Cardiology. 2001;37(2):379-85

8. Maeda K, Tsutamoto T, Wada A, Hisanaga T, Kinoshita M. Plasma brain natriuretic peptide as a biochemical marker of high left ventricular end-diastolic pressure in patients with symptomatic left ventricular dysfunction. American heart journal. 1998;135(5):825-32

9. Maisel AS, Krishnaswamy P, Nowak RM, McCord J, Hollander JE, Duc P, et al. Rapid measurement of B-type natriuretic peptide in the emergency diagnosis of heart failure. New England Journal of Medicine. 2002;347(3):161-7

10. Tulevski II, Groenink M, van Der Wall EE, Van Veldhuisen DJ, Boomsma F, Stoker J, et al. Increased brain and atrial natriuretic peptides in patients with chronic right ventricular pressure overload: correlation between plasma neurohormones and right ventricular dysfunction. Heart. 2001;86(1):27-30

11. Goyal BM, Sharma SM, Walia M. B-type natriuretic peptide levels predict extent and severity of coronary artery disease in non-ST elevation acute coronary syndrome and normal left ventricular function. Indian heart journal. 2014;66(2):183-7

12. Lellouche N, De Diego C, Cesario DA, Vaseghi M, Horowitz BN, Mahajan A, et al. Usefulness of preimplantation B-type natriuretic peptide level for predicting response to cardiac resynchronization therapy. The American journal of cardiology. 2007;99(2):242-6

13. Redfield MM, Rodeheffer RJ, Jacobsen SJ, Mahoney DW, Bailey KR, Burnett JC. Plasma brain natriuretic peptide concentration: impact of age and gender. Journal of the American College of Cardiology. 2002;40(5):976-82

14. Haug C, Metzele A, Steffgen J, Kochs M, Hombach V, Grünert A. Increased brain natriuretic peptide and atrial natriuretic peptide plasma concentrations in dialysis-dependent chronic renal failure and in patients with elevated left ventricular filling pressure. The clinical investigator. 1994;72(6):430-4

15. Deschamps J, Webber J, Featherstone R, Sebastianski M, Vandermeer B, Senaratne J, et al. Brain natriuretic peptide to predict successful liberation from mechanical ventilation in critically ill patients: protocol for a systematic review and meta-analysis. BMJ open. 2019;9(2):e022600

16. Martinez-Rumayor A, Richards AM, Burnett JC, Januzzi Jr JL. Biology of the natriuretic peptides. The American journal of cardiology. 2008;101(3):S3-8

17. Cowie MR, Struthers AD, Wood DA, Coats AJ, Thompson SG, Poole-Wilson PA, Sutton GC. Value of natriuretic peptides in assessment of patients with possible new heart failure in primary care. The Lancet. 1997;350(9088):1349-53

18. Chien JY, Lin MS, Huang YC, Chien YF, Yu CJ, Yang PC. Changes in B-type natriuretic peptide improve weaning outcome predicted by spontaneous breathing trial. Critical care medicine. 2008;36(5):1421-6

19. El Maraghi S, Hosny M, Samir M, Radwan W. Usage of Btype natriuretic peptide for prediction of weaning outcome by spontaneous breathing trial. Egyptian Journal of Chest Diseases and Tuberculosis. 2014;63(3):671-8.

20. Goetze JP, Gore A, Møller CH, Steinbrïchel DA, Rehfeld JF, Nielsen LB. Acute myocardial hypoxia increases BNP gene expression. The FASEB journal. 2004;18(15):1928-30

21. Amdani SM, Mian MU, Thomas RL, Ross RD. NT-pro BNP-A marker for worsening respiratory status and mortality in infants and young children with pulmonary hypertension. Congenital heart disease. 2018;13(4):499-505 